\title{
Predictors of micronutrient status in men and women over 75 years old living in the community*
}

\author{
Geraldine McNeill ${ }^{1} \dagger$, Juliet Vyvyan ${ }^{1}$, Heather Peace ${ }^{1}$, Linda McKie $^{2}$, Gwyn Seymour $^{1}$, Judith Hendry ${ }^{3}$ \\ and Isobel MacPherson ${ }^{2}$ \\ Departments of ${ }^{1}$ Medicine and Therapeutics and ${ }^{2}$ General Practice, University of Aberdeen, Foresterhill, \\ Aberdeen AB25 2ZD, UK \\ ${ }^{3}$ Community Dietetics, Grampian Primary Care NHS Trust, Aberdeen, UK
}

(Received 24 September 2001 - Revised 16 June 2002 - Accepted 15 July 2002)

\begin{abstract}
Serum ferritin, serum vitamin $B_{12}$, erythrocyte folate, plasma vitamin $C$ and plasma 25-hydroxycholecalciferol levels were measured in 208 men and 197 women, $>75$ years old and living in the community, in order to assess micronutrient status. Anthropometric measurements (height, weight, demispan and mid-upper arm circumference) were made and a 114-item questionnaire covering a wide range of health and diet-related topics was administered by an interviewer. Only $4 \%$ of subjects had a BMI $<20$, but the prevalence of marginal deficiency of the micronutrients ranged from $7 \%$ for Fe to $47 \%$ for vitamin D. There was no association between low micronutrient status (defined as being in the lowest third of the distribution of micronutrient status) and having BMI or mid-upper arm circumference in the lowest third of the distribution for any of the nutrients. Leaving food on the plate was strongly associated with both low $\mathrm{Fe}$ status and low vitamin D status. Having breakfast cereal less than once per week was strongly associated with low folate status, while having fresh fruit juice less than once per week, having had less than two portions of fruits and vegetables the previous day and believing that food is not important for health were strongly associated with low vitamin C status. Low vitamin D status was strongly associated with a wide range of general health and disability measures. Having a weekly household income of less than $£ 150$ was associated with low status of $\mathrm{Fe}$, folate, vitamin C and vitamin D.
\end{abstract}

Nutritional deficiency: Anthropometric measurements: Elderly

In recent years, evidence has been accumulating that the diet of the elderly has an impact on morbidity and mortality. Several studies have shown that dietary patterns that conform to healthy eating guidelines are associated with increased overall survival (Trichopolou et al. 1995; Huijbregts et al. 1997; Kumagai et al. 1999). Generalised health consequences of low micronutrient status may include reduced immune function (Lesourd \& Mazari, 1999), impaired cognitive function (Selhub et al. 2000) and increased risk of complications during hospitalisation (Larsson, 1993). More recent studies have suggested that there may be an increased risk of stroke in elderly people with low vitamin C intake (Gale et al. 1995) and an increased risk of CHD in those with low fruit and vegetable consumption and folate status (Eicholzer et al. 2001).

Although elderly people in hospitals and residential care are known to be at high risk of nutritional problems, elderly people living in the community are also at greater risk of nutritional problems than younger adults (Steen \& Rothenberg, 1998). The classical picture of malnutrition in the elderly is one of generalised malnutrition with low body mass and muscle wasting. However, it is now recognised that: 'besides a clinical, clearly visible malnutrition, selective nutrient deficits are much more frequent' (Stähelin, 1999). This may be because ageing is associated with a reduction in energy requirements due to a loss of lean tissue mass and a decline in physical activity. As a result, older people may be able to maintain body weight on a low energy intake, but will be at risk of specific deficiencies unless their diet includes foods that are rich in micronutrients.

The growing awareness of the importance of nutrition in the elderly in recent years has led to the development of several nutrition assessment tools such as the Nutrition

\footnotetext{
Abbreviation: OR, odds ratio.

*Copies of the full questionnaire used in the present study are available from the corresponding author on request.

$\dagger$ Corresponding author: Dr Geraldine McNeill, fax +44 1224 663658, email g.mcneill@abdn.ac.uk
} 
Screening Initiative (Lipschitz et al. 1992) and the Mini Nutritional Assessment (Guigoz et al. 1994). These tools include general questions on appetite and weight loss and incorporate assessment of protein-energy malnutrition through anthropometric measurements and routine hospital laboratory tests such as serum albumin or cholesterol. Although Mini Nutritional Assessment scores have recently been shown to be associated with blood measures of a number of micronutrients (Vellas et al. 2000), the score does not provide information on the likelihood of micronutrient deficiencies in individuals. Without access to laboratory tests of nutritional status, health professionals working in the community have little opportunity to assess the risk of a given micronutrient deficiency in their patients and to give appropriate nutritional advice.

In the UK, primary care professionals offer an annual health check to all patients $>75$ years old, although the components of this check can vary between practices (Brown et al. 1997). In an earlier study, we identified dietary beliefs and practices of people $>75$ years old living in the community (McKie et al. 2000). Building on this information, we set out to identify factors associated with low micronutrient status, in men and women living in the community, that could be incorporated into a screening tool to be used in the health check for those $>75$ years old.

\section{Participants and methods}

\section{Subjects}

Names and addresses of a random sample of those $>75$ years old living in the community in Aberdeen, Grampian, UK, were obtained from the local Community Health Index, a register of all patients registered with a general practitioner. Each patient's general practitioner was notified of our intention to approach their patient and was asked to exclude those suffering from dementia to the extent that they would have difficulty responding to an interview in their own home. Men ( $n$ 821) and women ( $n$ 1122) were sent a letter inviting them to participate, of whom 217 men $(25 \%)$ and 191 women $(17 \%)$ completed the study. Table 1 shows that the age distribution of the participants (using deprivation categories based on postcode) of those who participated was similar to that of the population of those $>75$ years old in the Grampian region. Results from the Carstairs deprivation category (derived from postcode) showed that in men the proportions in categories 1-2 (most affluent), 3-4 and 5-7 (most deprived) were very similar to the rest of the population, but in the women who participated, deprivation categories 1-2 were under-represented and 3-4 were over-represented ( $\left.\chi^{2} 9 \cdot 64, P<0 \cdot 01\right)$.

\section{Protocol}

All subjects were visited in their own home on two occasions. On the first visit, a detailed questionnaire about diet and health was administered. On the second visit, 1-14 d later, a research nurse took anthropometric measurements and a venous blood sample. The measurements were carried out over a 12-month period between April 1999 and March 2000. For the subjects seen in summer (June-September), repeat samples were taken in winter (February-March) to estimate seasonal change in vitamin D status. The study protocol was approved by Grampian Research Ethics Committee and all subjects gave written informed consent to participate.

\section{Questionnaire}

A questionnaire was developed for the present study to include a wide range of potential dietary and other risk factors for micronutrient deficiencies. As a result of an earlier project exploring attitudes and beliefs about diet in men and women $>75$ years old (McKie et al. 2000), questions on beliefs about the importance of food and self-motivation in relation to health and diet were included. The questionnaire included forty-two questions on general health (appetite, weight loss, medical conditions, medication, exercise and attitude towards health and diet), forty-two questions on intake of foods containing the nutrients of interest, twenty questions on disability in the form of the EASYcare Elderly Assessment System (Philp, 2000) and the ten-item Clifton Assessment Procedure for the Elderly (CAPE) orientation assessment (Pattie \& Gilleard, 1975).

The reproducibility of the responses to each item was assessed in twenty-nine men and twenty-nine women: for $57 \%$ of questions the values of Cohen's kappa or Kendall's tau-b were $>0.6$ and for $20 \%$ the values were $>0.8$ (Vyvyan et al. 2000). All questionnaires were administered by the same interviewer and data from the questionnaire were entered into a personal computer using the Teleform

Table 1. Distribution (\%) of age and deprivation scores in participants compared with the rest of Grampian population aged $>75$ years old ${ }^{\star}$

\begin{tabular}{|c|c|c|c|c|c|c|c|}
\hline & \multirow[b]{2}{*}{$n$} & \multicolumn{3}{|c|}{ Age category (years) } & \multicolumn{3}{|c|}{ Deprivation category $†$} \\
\hline & & $75-79$ & $80-84$ & $>85$ & $1-2$ & $3-4$ & $5-7$ \\
\hline \multicolumn{8}{|l|}{ Men } \\
\hline Present study & 207 & $51 \cdot 7$ & 31.4 & $16 \cdot 9$ & $49 \cdot 8$ & $28 \cdot 0$ & $22 \cdot 2$ \\
\hline Rest of Grampian & 11426 & 53.3 & 27.4 & $19 \cdot 3$ & $50 \cdot 1$ & 28.0 & 21.9 \\
\hline \multicolumn{8}{|l|}{ Women } \\
\hline Present study & 191 & 44.5 & 31.9 & $23 \cdot 6$ & 41.9 & $36 \cdot 6$ & 21.5 \\
\hline Rest of Grampian & 21697 & $42 \cdot 2$ & 28.4 & 29.4 & $50 \cdot 8$ & $27 \cdot 4$ & 21.9 \\
\hline
\end{tabular}

* For details of subjects, see Table 2 and p. 556.

† Carstairs \& Morris (1990). 
data entry package version 5 (Cardiff software, Vista, CA, USA).

\section{Anthropometric measurements}

Weight was measured to the nearest $0.1 \mathrm{~kg}$ on Soehle bathroom scales (CMS Weighing, London, UK) that were calibrated with standard weights at intervals during the measurement period. Subjects wore indoor clothing but no shoes for the measurements. Height was measured to the nearest $0.001 \mathrm{~m}$ using a portable stadiometer (Leicester Height Measure; CMS Weighing). Demispan was measured as the distance between the sternal notch and the web space between the third and fourth fingers on the left hand (or the right hand if the left arm could not be fully extended), using a tape designed for the purpose (CMS Weighing). Mid-arm circumference was measured as the circumference of the upper left arm mid-way between the acromion and olecranon processes, with the arm hanging loosely at the side. BMI was calculated as weight $(\mathrm{kg}) / \mathrm{height}(\mathrm{m})^{2}$; demiquet was calculated as weight $(\mathrm{kg}) /$ demispan $(\mathrm{m})^{2}$ in men, and mindex was calculated as weight $(\mathrm{kg}) /$ demispan $(\mathrm{m})$ in women (Lehmann et al. 1991). In twenty-one subjects (eleven men and ten women), height measurements were considered unreliable as the subjects had difficulty standing erect, and in five subjects (three men and two women) the demispan was considered unreliable as the subjects could not extend either arm fully. These subjects were excluded from the analyses involving anthropometric measurements.

\section{Blood measurements}

Blood samples were taken after a light breakfast of tea and/ or white bread or toast, with no fruit juice or breakfast cereals allowed prior to the sample. Samples were stored on ice for transport to the laboratories within $2 \mathrm{~h}$ of collection. Samples for ferritin, vitamin $\mathrm{B}_{12}$ and serum and erythrocyte folate were taken to the haematology laboratory at Grampian University Hospitals; samples for vitamin D were frozen at $-70^{\circ} \mathrm{C}$ and samples for vitamin $\mathrm{C}$ were treated with metaphosphoric acid and frozen at $-70^{\circ} \mathrm{C}$. Serum ferritin, serum vitamin $\mathrm{B}_{12}$ and serum and erythrocyte folate were analysed by a Technicon Immuno 1 radioimmunoassay (), with quality control assessed under the UK External Quality Assessment Scheme for Haematology. Plasma vitamin $\mathrm{C}$ samples were analysed by reversedphase HPLC using an ion-pairing reagent with u.v. detection (Ross, 1994) as described by Duthie (1999). Serum 25-hydroxycholecalciferol was measured in duplicate using a manual extraction radioimmunoassay (Diasorin Ltd, Saluggia, Italy). The functional sensitivity of this assay is $6 \mathrm{nmol} / 1$ and the $\mathrm{CV}$ is $<8 \%$ across the concentration range $15-1000 \mathrm{nmol} / \mathrm{l}$. The assay cross-reacts on an equimolar basis with 25-hydroxy vitamin $\mathrm{D}_{3}$ and 25hydroxy vitamin $\mathrm{D}_{2}$. There was no significant difference in ferritin levels between the nine men and seven women who had leucocyte counts $>10 \times 10^{9} / 1$ and those with lower leucocyte counts, so all ferritin results were included in the analysis. Cut-off points for deficiency were chosen at the upper end of the range of published values, as they were designed to estimate the prevalence of marginal deficiency states rather than established clinical deficiency.

\section{Data analysis}

Responses to each item on the questionnaire were classified as either 'high risk' or 'low risk'. The cut-off point selected was based on the distribution of the responses to the original question, so that the 'high risk' group did not contain $<15$ or $>50 \%$ of the subjects. The anthropometric measurements and blood results were classified as low or normal using the 33rd percentile as the cut-off point. Men and women were combined to define these cut-off points for BMI and blood measures, as there was no reason a priori to assume that the relationship between predictor variables and blood measurements would be different between gender. The 33rd percentiles were: BMI $23.9 \mathrm{~kg} / \mathrm{m}^{2}$; demiquet $106.3 \mathrm{~kg} / \mathrm{m}^{2} ;$ mindex $78.9 \mathrm{~kg} / \mathrm{m}$; mid-arm circumference $0.29 \mathrm{~m}$. The $33 \mathrm{rd}$ percentiles of

Table 2. Characteristics of study subjects*

(Median values and ranges)

\begin{tabular}{|c|c|c|c|c|}
\hline & \multicolumn{2}{|c|}{ Men ( $n$ 207) } & \multicolumn{2}{|c|}{ Women (n 191) } \\
\hline & Median & Range & Median & Range \\
\hline Age (years) & 79 & $75-93$ & 80 & $75-96$ \\
\hline $\mathrm{BMI}\left(\mathrm{kg} / \mathrm{m}^{2}\right) \dagger$ & $25 \cdot 3$ & $16 \cdot 6-35 \cdot 0$ & $25 \cdot 6$ & $16 \cdot 6-34 \cdot 1$ \\
\hline Demiquet $\left(\mathrm{kg} / \mathrm{m}^{2}\right) \ddagger$ & $112 \cdot 8$ & $74.9-155.7$ & $\mathrm{n} / \mathrm{a}$ & $\mathrm{n} / \mathrm{a}$ \\
\hline Mindex $(\mathrm{kg} / \mathrm{m}) \S$ & $\mathrm{n} / \mathrm{a}$ & $\mathrm{n} / \mathrm{a}$ & 85.4 & $58 \cdot 8-184 \cdot 2$ \\
\hline Mid-arm circumference $(\mathrm{m})$ & 0.302 & $0.219-0.384$ & 0.300 & $0.210-0.402$ \\
\hline Serum ferritin $(\mu \mathrm{g} / \mathrm{l})$ & 74.9 & $3 \cdot 8-1847$ & $47 \cdot 6$ & $4.4-1232$ \\
\hline Serum vitamin $\mathrm{B}_{12}(\mathrm{pmol} / \mathrm{l})$ & 244 & $39-1474$ & 247 & $74-1474$ \\
\hline Erythrocyte folate $(\mathrm{nmol} / \mathrm{l}) \|$ & 607 & $66-2268$ & 544 & $107-2179$ \\
\hline Plasma vitamin C ( $\mu \mathrm{mol} / /)$ & $35 \cdot 7$ & $0-137.9$ & $45 \cdot 6$ & $0-131 \cdot 2$ \\
\hline Serum 25-hydroxycholecalciferol (nmol//) & 33.0 & $6 \cdot 0-82 \cdot 0$ & $28 \cdot 0$ & $70-82 \cdot 0$ \\
\hline
\end{tabular}

n/a, Not applicable.

* For details of procedures, see p. 556.

t $n 190$ men and 181 women.

$\ddagger n 204$ men.

$\S n 189$ women.

\|n 204 men and 187 women. 
the blood results were: ferritin $38.3 \mu \mathrm{g} / \mathrm{l}$; vitamin $\mathrm{B}_{12}$ $208 \mathrm{pmol} / \mathrm{l}$; erythrocyte folate $458 \mathrm{nmol} / \mathrm{l}$; vitamin $\mathrm{C}$ $27.7 \mu \mathrm{mol} / \mathrm{l} ; 25$-hydroxycholecalciferol $25 \mathrm{nmol} / \mathrm{l}$. Associations between being at high $v$. low risk according to the questionnaire items or having low $v$. normal anthropometric measurements and having low $v$. normal blood measurements were assessed with Mantel-Haenszel odds ratios (OR). Those taking dietary supplements were excluded from calculations of OR for nutrients contained in the supplement. Comparisons between serum 25-hyroxycholecaliferol in summer and winter were carried out by paired $t$ test on log-transformed data. All analyses were carried out with SPSS version 10.0 (SPSS, Chicago, IL, USA).

\section{Results}

The age, anthropometric measurements and blood levels of micronutrient status in the subjects are given in Table 2 . Only $4.1 \%$ of men and $3.9 \%$ of women had a BMI $<20$, while $5.6 \%$ of men and $12.2 \%$ of women had a BMI $>30$. Of men, $34 \%$ lived alone and of women, $69 \%$. Subjects taking supplements containing $\mathrm{Fe}$, vitamin $\mathrm{B}_{12}$, folate, vitamin $\mathrm{C}$ and vitamin $\mathrm{D}$ were $8,9,9,12$ and $24 \%$ of men and $6,10,9,15$ and $30 \%$ of women respectively.

The cut-off points used to define marginal micronutrient deficiency and the prevalence of marginal deficiency of the five micronutrients in the total study population are shown in Table 3. For Fe, vitamin $\mathrm{B}_{12}$ and folate the prevalence of marginal deficiency was fairly similar in men and women, but marginal deficiency of vitamin $\mathrm{C}$ was more common in men, while marginal deficiency of vitamin D was more common in women. Those aged $\geq 80$ years old were not more likely to have low micronutrient status than those aged 75-79 years old except in the case of vitamin D deficiency (OR 2.23; $95 \%$ CI 1.35, 3.66). Season was also a determinant of vitamin D status: in thirty-one men and twenty-four women who had samples taken in the summer and winter the median 25-hydroxycholecalciferol levels were 31 (range 9-78) $\mathrm{nmol} / \mathrm{l}$ in summer compared with 24 (range 7-92) nmol/l in winter $(P<0 \cdot 001)$.
BMI, demiquet, mindex and mid-arm circumference were poor predictors of low micronutrient status: there were no significant associations between being in the lowest third of these measurements and having blood levels in the lowest third for any of the five nutrients apart from an association between mindex and serum ferritin in women (OR 2.36; $95 \%$ CI 1.21-4.46). Dietary supplements of the specific nutrient were associated with being in the middle or upper third of blood levels of vitamin $\mathrm{B}_{12}$, folate, vitamin $\mathrm{C}$ and 25-hydroxycholecalciferol (OR (95\% CI): 2.73 (1.11, 6.73), 18.15 (2.49, $132.33), 4.29(1.78,10.32)$ and $8.17(4.09,16.29)$ respectively); but the association between taking supplements containing $\mathrm{Fe}$ and being in the middle or upper third of the distribution of serum ferritin was not statistically significant (OR 1.89; $95 \%$ CI 0.75, 4.79). Apart from taking supplements containing vitamin $\mathrm{B}_{12}$, the only significant predictor of being in the lowest third of the distribution of vitamin $\mathrm{B}_{12}$ status was not having any natural teeth (OR 1.71; $95 \%$ CI 1.09, 2.70).

Table 4 shows the items from the questionnaire for which the 'high risk' responses were associated with low $\mathrm{Fe}$, folate, vitamin $\mathrm{C}$ or vitamin $\mathrm{D}$ status. There were a further twelve questions (age, living alone, recent weight loss, not seeing people often, having heart problems, having oily fish less than once per month, having difficulty seeing, standing, holding cooking pans, opening tins or bathing, and overall EASY-care score (Philp, 2000)) that were strongly associated with having low vitamin $\mathrm{D}$ but not $\mathrm{Fe}$, folate or vitamin $\mathrm{C}$ status (all $P<0.01$ ). The only item associated with low status of all four nutrients was having an income of less than $£ 150$ per week.

The data were also analysed comparing the questionnaire items shown in Table 3 with having marginal deficiency of the micronutrients as opposed to being in the lowest third of the distribution of blood levels. For $\mathrm{Fe}$ and vitamin $\mathrm{B}_{12}$, none of the factors showed any significant associations, though due to the low prevalence of marginal deficiency of these nutrients the power of these tests was low. For folate, marginal deficiency was associated with having breakfast cereal less than once per week (OR 2.83; $95 \%$ CI 1.61, 4.97), having less than two

Table 3. Cut-off points for marginal deficiency and prevalence of marginal deficiency in the study population*

\begin{tabular}{|c|c|c|c|c|}
\hline & \multicolumn{2}{|c|}{ Men ( $n$ 207) } & \multicolumn{2}{|c|}{ Women (n 191) } \\
\hline & Cut-off point & Prevalence (\%) & Cut-off point & Prevalence (\%) \\
\hline Serum ferritin $(\mu \mathrm{g} / \mathrm{l})$ & $20 \dagger$ & $6 \cdot 3$ & $15 \dagger$ & $7 \cdot 3$ \\
\hline Serum vitamin $\mathrm{B}_{12}(\mathrm{pmol} / \mathrm{l})$ & $147 \ddagger$ & $10 \cdot 1$ & $147 \ddagger$ & $12 \cdot 6$ \\
\hline Erythrocyte folate $(\mathrm{nmol} / \mathrm{l}) \S$ & 3569 & 14.5 & 3560 & $16 \cdot 8$ \\
\hline Plasma vitamin C ( $\mu \mathrm{mol} / /)$ & $23 \|$ & 32.9 & $23 \|$ & 24.6 \\
\hline Serum 25-hydroxycholecalciferol (nmol/l) & $30^{\star \star}$ & $37 \cdot 2$ & $30^{* \star}$ & $56 \cdot 5$ \\
\hline
\end{tabular}

${ }^{*}$ For details of subjects and procedures, see Tables 1 and 2 and p. 556

† International Nutritional Anemia Consultative Group (1985).

$\ddagger$ World Health Organization (1968).

§n 204 men, 187 women.

\|l Sauberlich (1977).

I Sauberlich et al. (1974).

** Sauberlich (1999). 
Table 4. Odds ratios for being in the low rather than middle or high third of the distribution of blood micronutrient levels

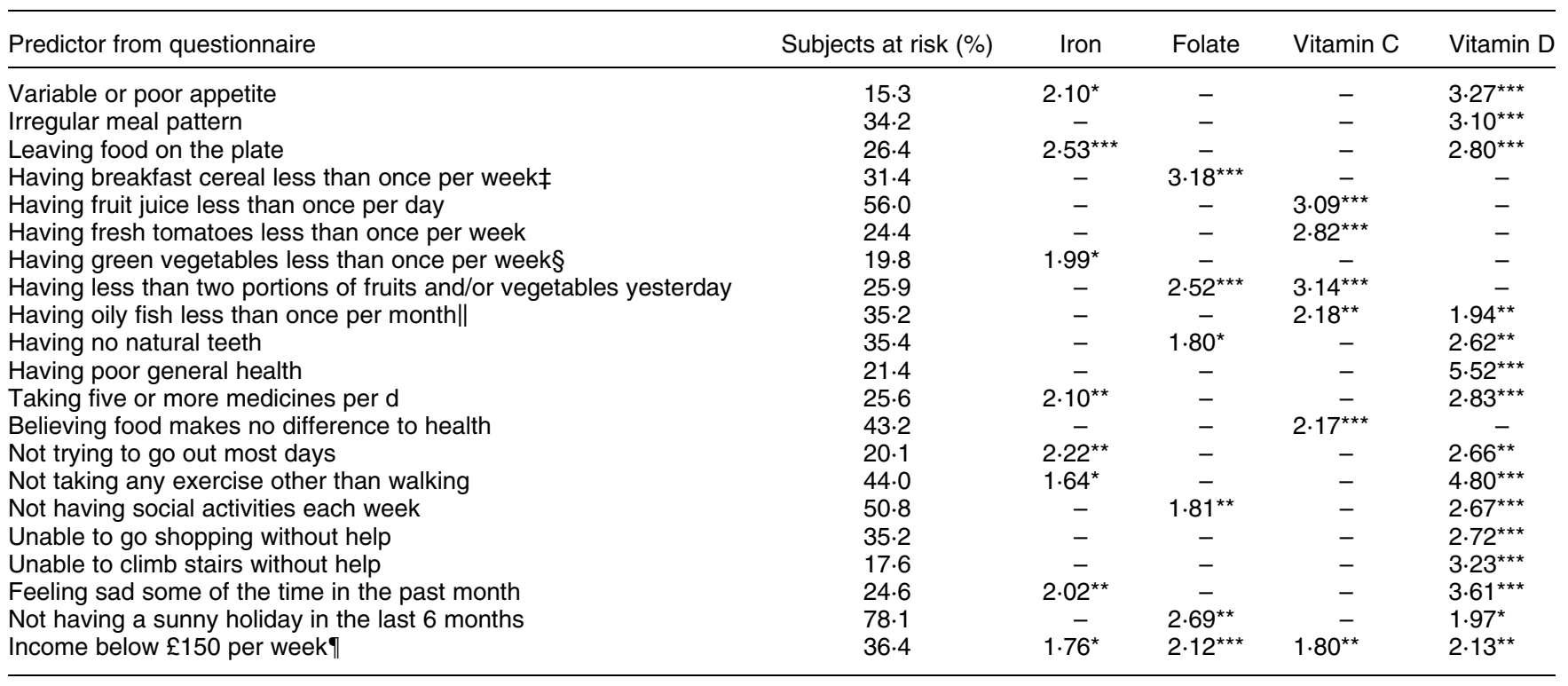

${ }^{*} P<0.05,{ }^{* *} P<0.01,{ }^{* * *} P<0.001$

†For details of subjects and procedures, see Tables 1 and 2 and p. 556

† Fortified and unfortified cereals.

$\S$ Cabbage, broccoli, spinach etc., but not peas or green beans.

\| Herring or kippers, mackerel and salmon.

q Combined income for couples.

portions of fruits and/or vegetables the previous day (OR 1.92; $95 \%$ CI 1.07, 3.43) and having a household income less than $£ 150$ per week (OR 1.96; $95 \%$ CI 1.12, 3.41). For vitamin $\mathrm{C}$ and vitamin $\mathrm{D}$, the associations were very similar to those shown in Table 4.

\section{Discussion}

Although there was little anthropometric evidence of malnutrition in these men and women, marginal deficiency of micronutrients was not uncommon, particularly for vitamin $\mathrm{C}$ and vitamin $\mathrm{D}$. A high prevalence of marginal deficiency of vitamin D may be expected on the basis of the northerly latitude of the present study location $\left(58^{\circ} \mathrm{N}\right)$, but for the other four micronutrients the median levels in subjects aged 75-84 years in the present study were higher than those in community-living subjects of the same age in a recent UK-wide survey (Finch et al. 1998) apart from ferritin levels in men, suggesting that our subjects were not unusually malnourished with regard to these nutrients compared with the UK population. Compared with results on vitamin $\mathrm{B}_{12}$, folate and vitamin $\mathrm{D}$ in 2600 men and women aged 80-85 years old living in the community in a range of European countries in the Survey in Europe on Nutrition and the Elderly: a Concerted Action (SENECA) study (Haller, 1999), the median values in our present subjects were towards the lower end of the range of values seen in the eleven different countries, particularly for vitamin $B_{12}$. However, caution is needed in comparing results from different laboratories, as large inter-laboratory variations may occur, particularly in the case of folate levels (Gunter et al. 1996).

The lack of association between anthropometric measures and micronutrient status in the present study supports the suggestion that in the elderly, micronutrient deficiencies can occur without generalised protein-energy malnutrition. This is in agreement with an analysis of data from 570 men and 554 women aged 70-75 years in the SENECA study, which showed no relationship between anthropometric indices and plasma vitamin $\mathrm{B}_{12}$ or folate levels (Weggemans et al. 1997). We also found no relationship between reported weight loss and low $\mathrm{Fe}$, vitamin $\mathrm{B}_{12}$, folate or vitamin $\mathrm{C}$ status, although there was an association with low vitamin D status (OR 2.09; $95 \%$ CI 1.22, 3.56). Due to the cross-sectional nature of the present study, we were not able to assess whether clinical measurements of weight change could predict micronutrient deficiency, but this possibility merits testing in future studies. In our test-retest studies, self-reported weight loss in the past 6 months was found to have low reproducibility (Kendall's tau-b 0.17), indicating that in this population it may not provide a reliable estimate of actual weight change.

Of the 114 items on the questionnaire, only four items were strongly associated $(P<0 \cdot 01)$ with low Fe status, five with low folate status and six with low vitamin $C$ status, while twenty-five items were strongly associated with low vitamin D status. It is important to recognise that in this kind of exploratory data analysis with multiple significance tests, weak associations may easily arise by chance, and $P$ values of 0.05 should be treated with caution. Many of the associations with $P<0.01$ are plausible as causal associations, for example, not going out most days could directly affect vitamin D status. The associations between breakfast cereal consumption and folate status and between fresh fruit juice consumption and 
vitamin C status could clearly be causal and are all the more convincing in light of the fact that similar associations were also found in an analysis of the national survey data (Gibson, 1998). Other associations may reflect the confounding influence of a third variable, for example, the association between fish intake and vitamin $\mathrm{C}$ status could reflect the fact that those who eat more fish also eat more fruits and vegetables. These associations are more likely to be population-specific and may not therefore be valid in other elderly populations with a different diet or lifestyle. The lack of association between questionnaire items and vitamin $\mathrm{B}_{12}$ deficiency may be accounted for by the fact that vitamin $\mathrm{B}_{12}$ deficiency is more likely to be the result of atrophic gastritis than dietary inadequacy.

The lack of association between anthropometric measurements and micronutrient status in this population indicates that screening tools that focus on proteinenergy malnutrition and anthropometric measurements may not be useful for identifying those at risk of micronutrient deficiency. However, the high prevalence of marginal deficiency in this population (Table 3) demonstrates that there is a need for simple dietary advice about intake of key foods and/or micronutrient supplements for those at risk of these deficiencies. From the present study, specific questionnaire items appear to be useful in identifying those at risk and in drawing attention to areas on which dietary advice could be focused. These questionnaire items now need to be compared with biochemical measures of micronutrient status in other populations to assess the possibility of wider application of these findings.

\section{Acknowledgements}

The present study was supported by a grant from the Scottish Office (Chief Scientist Office); ref K/OPR/2/2/D334. We thank Anne Ball, Barbara O'Hanrahan, Dr Graham Beatsall, Dr Garry Duthie, Dr Derek King, Grampian GPs and the subjects who participated for their contributions to this study.

\section{References}

Brown K, Boot D, Groom L \& Williams EI (1997) Problems found in the over-75s by the annual health check. British Journal of General Practice 47, 31-35.

Carstairs V \& Morris R (1990) Deprivation and Health in Scotland. Health Bulletin (Edinburgh) 48, 162-175.

Duthie GG (1999) Determination of activity of antioxidants in human subjects. Proceedings of the Nutrition Society 58, 1015-1024.

Eicholzer M, Luthy J, Gutzwiller F \& Stahelin HB (2001) The role of folate, antioxidant vitamins and other constituents in fruit and vegetables in the prevention of cardiovascular disease: the epidemiological evidence. International Journal of Vitamin and Nutrition Research 71, 5-17.

Finch S, Doyle W, Lowe C, Bates CJ, Prentice A, Smithers G \& Clarke PC (1998) National Diet and Nutrition Survey: People Aged 65 Years and Over. London: The Stationery Office.

Gale CR, Martyn CN, Winter PD \& Cooper C (1995) Vitamin C and risk of death from stroke and coronary heart disease in cohort of elderly people. British Medical Journal 310, $1563-1566$.
Gibson SA (1998) Computer Models to Identify Individuals at Risk of Poor Micronutrient Status in the Population Aged 65 years and Older. Ministry of Agriculture, Fisheries and Food Report no. AN0834. London: MAFF.

Gunter EW, Bowman BA, Caudill SP, Twite DB, Adams MJ \& Sampson EJ (1996) Results of an international round robin for serum and whole-blood folate. Clinical Chemistry 42, $1689-1694$.

Guigoz Y, Vellas B \& Garry PJ (1994) Mini-Nutritional Assessment: a practical assessment tool for grading the nutritional state of elderly patients. Facts and Research in Gerontology Suppl. 2, 15-59.

Haller J (1999) The vitamin status and its adequacy in the elderly - an international overview. International Journal of Vitamin and Nutrition Research 89, 160-168.

Huijbregts P, Feskens E, Rasanen L, Fidanza K, Nissinen A, Menotti A \& Kromhout D (1997) Dietary patterns and 20 year mortality in elderly men in Finland, Italy and the Netherlands: longitudinal cohort study. British Medical Journal 315, $13-17$.

International Nutritional Anemia Consultative Group (1985) Measurement of Iron Status. A Report of the International Nutritional Anemia Consultative Group. Washington, DC: The Nutrition Foundation.

Kumagai S, Shibata H, Watanabe S, Suzuki T \& Haga H (1999) Effect of food intake pattern on all-cause mortality in the community elderly: a 7-year longitudinal study. Journal of Nutrition, Health and Aging 3, 29-33.

Larsson J (1993) Clinical problem of hospital malnutrition. Nutrition 9, 274-275.

Lehmann A, Bassey EJ, Morgan K \& Dallosso HM (1991) Normal values for weight, height, skeletal size and body mass indices in 890 men and women aged over $65 \mathrm{y}$. Clinical Nutrition 10, 18-22.

Lesourd B \& Mazari L (1999) Nutrition and immunity in the elderly. Proceedings of the Nutrition Society 58, 685-695.

Lipschitz DA, Ham RJ \& White JV (1992) An approach to nutrition screening for older Americans. American Family Physician 45, 601-608.

McKie L, MacInnes A, Hendry J, Donald S \& Peace H (2000) The food consumption patterns and perceptions of dietary advice of older people. Journal of Human Nutrition and Dietetics 13, 173-183.

Pattie AH \& Gilleard CJ (1975) A brief psychogeriatric assessment schedule. Validation against psychiatric diagnosis and discharge from hospital. British Journal of Psychiatry 127, 489-493.

Philp I (2000) EASY-care: A systematic approach to the assessment of older people. Geriatric Medicine 30, 15-19.

Ross M (1994) Determination of ascorbic acid and uric acid in plasma by high-performance liquid chromatography. Journal of Chromatography B 657, 197-200.

Sauberlich HE (1977) Detection of folic acid deficiency in populations. In Folic Acid: Biochemistry and Physiology in Relation to the Human Nutrition Requirement. Washington, DC: Food and Nutrition Board, National Academy of Sciences.

Sauberlich HE (1999) Laboratory Tests for the Assessment of Nutritional Status, 2nd ed. Boca Raton, FL: CRC Press.

Sauberlich HE, Dowdy RP \& Skala JH (1974) Laboratory Tests for the Assessment of Nutritional Status. Boca Raton, FL: CRC Press.

Selhub J, Bagley LC, Miller J \& Rosenberg IL (2000) B vitamins, homocysteine, and neurocognitive function in the elderly. American Journal of Clinical Nutrition 71, 614S-620S.

Stähelin HB (1999) Introduction. In Malnutrition in the Elderly [WO Seiler and HB Stähelin, editors]. Darmstadt: Steinkopf.

Steen B \& Rothenberg E (1998) Aspects of nutrition of the 
elderly at home - a review. Journal of Nutrition, Health and Aging 2, 28-33.

Trichopolou A, Kouris-Blazos A, Wahlqvist M, Gnardellis C, Laigon P, Polychronopoulos P, Vassilakou T, Lipworth L \& Trichopoulos D (1995) Diet and overall survival in elderly people. British Medical Journal 311, 1457-1460.

Vellas B, Guigoz Y, Baumgartner M, Garry PJ, Lauque S \& Albarede JL (2000) Relationships between nutritional markers and the mini-nutritional assessment in 155 older persons. Journal of the American Geriatric Society 48, 1300-1309.
Vyvyan J, O’Hanrahan BT, Franklin MF \& McNeill G (2000) Reliability of responses to diet-related questions in people over 75y. Revista Espanola de Geriatria y Gerontologia 35, 383.

Weggemans RM, de Groot LC \& Haller J (1997) Factors related to plasma folate and vitamin $B_{12}$. The SENECA study. International Journal of Food Science and Nutrition 48, $141-150$.

World Health Organization (1968) Nutritional Anaemias. World Health Organization Technical Report Series no. 401. Geneva: WHO. 